\title{
Problems with the Diamond's Paradox in Searching for Experts*
}

Ken Aoki, M. A."

Some studies applied the search model to the market for expert services; the model showed that an equilibrium exists where experts convey factual information to customers. However, we demonstrate that such a desirable equilibrium vanishes by replacing the original assumptions with more plausible assumptions. This shows the limitation of using customer search as a mechanism of disciplining experts' fraudulent behavior.

Keywords : Expert service, Credence goods, Asymmetric information, Search

\section{Introduction}

Services such as medical care and automotive repair services share a common feature: the supplier of the service is also an expert who determines how much of the service is needed. Often, customers cannot determine whether the service provided is really needed. Darby and Karni (1973) named this type of service 'credence goods'.

Common features of credence goods give experts incentive for opportunistic behavior, or in other words, for fraudulent behavior ${ }^{1}$. What mechanism can prevent experts from engaging in fraudulent behavior? Some studies have utilized customer search as a device for disciplining experts, Pitchik and Schotter (1993) and Wolinsky (1993).

\footnotetext{
\# Faculty of Economics, Sophia University
}

The search story is based on an intuition -if customers are prescribed an expensive service, they may seek another expert's opinion. Experts who are afraid of losing customers to competitors would tell the truth. This intuition is usually modeled under a two-type as-

* This work was started while I was visiting the Asia/ Pacific Research Center at Stanford University in 1998. I wish to thank their hospitality during my visit. An earlier version of this paper was presented at the 1998 annual meeting of the Japanese Economic Association and the 1999 health economics seminar at the Health Care Science Institute. I would like to thank M. Tsuji, M. Nakaizumi, and seminar participants for their helpful comments. Especially; I gratefully acknowledge very valuable suggestions from the late Satoshi Nakanishi, who led me to the research in health economics. This research was partially supported by Research Fellowships of the Japan Society for the Promotion of Science for Young Scientists and KAKENHI (14730052). Any remaining errors are the sole responsibility of the author. 
sumption such as customers' problem types (light or heavy) and experts' service types (cheap or expensive). A model with a twotype assumption gives a desirable equilibrium in which experts transmit true information to customers.

However, in this study, we show that such a desirable equilibrium disappears when the two-type assumption is replaced with more plausible assumption. The new game has a unique Nash equilibrium in which experts prescribe the most expensive service regardless of severity and customers accept the advice with out searching. The reason the desirable equilibrium vanishes in our model is essentially the same as that which underlies the Diamond's paradox in price competition under a positive search cost ${ }^{2)}$. The most important reason is that a customer cannot make a commitment to search (i, e. seek other opinions). The purpose of this article is to show the limitation of

1) This is the essential idea behind physician induced demand hypothesis, PID. Some studies test empirically the PID hypothesis in Japanese health care market. (Nishimura, 1987 ; Suzuki, 1997 ; Izumida, Nakanishi and Urushi, 1999 ; Kishida, 2001 ; Yamada, 2002)

2) Let assume $N(\geq 2)$ firms have homogeneous constant marginal cost and consumers are homogeneous in preference and search cost. If consumers have zero search cost, all firms charge competitive price, Bertrand equilibrium. But if consumers have positive search cost, small the search cost is, and how many competitors there are. Diamond (1971) first pointed out such a result. We call the latter paradoxical phenomenon "Diamond's problem". A number of authors tried to solve this paradox and derived a equilibrium with price dispersion. McMillan and Rothschild (1994) and Stiglitz (1989) provide a excellent survey about such a studies. applying the search model to the credence goods market as a mechanism for disciplining experts even though the search model is intuitively plausible and previous studies have shown that the model worked. For this purpose, we construct a simple two experts duopoly model in section 2. The derived equilibria and Diamond's problem in this model are stated in section 3. Last section contains a few concluding remarks.

\section{The Model}

Players are classified into two populations, customers and experts. Continuum number of customers with total measure one possess a durable good such as health capital or car. Each of their durable goods has a problem, $\mathrm{L}$ (light) or $\mathrm{H}$ (heavy), and severities are different among customers. Each customer knows that his durable good has a problem, but does not know how severe it is. Let $t \in\{L, H\}$ denote the customer's severity and each frequency of $\mathrm{L}$ - and $\mathrm{H}$-problem in the population is $1 / 2$.

There are two experts in this market. They can identify severities through diagnosis with cost $d$ and can provide two kinds of service according to customers' severity. $c_{L}$-service can fix the L-problem with cost $c_{L}$ and $c_{H}$ service can fix the $\mathrm{H}$-problem with cost $c_{H}\left(>c_{L}\right)$. Both experts have homogeneous fixing costs, $c_{L}$ and $c_{H}$. We note that $c_{H}$-service can fix both the L-problem and H-problem, while $c_{L}$ service can fix only the L-problem. Therefore, customers who purchased $c_{I I}$-service never learn the severity of their problem. This feature the unique equilibrium is for all firms to charge monopoly price, no matter how high it is, how 
gives experts a chance for opportunistic behavior.

Each customer randomly chooses the expert he visits first and decides whether he will purchase the service from the expert he consulted. The customer can decide to purchase the service recommend to him or seek the opinion of another expert. He can get a second opinion with a search cost and an additional diagnosis cost. Every customer has the positive and homogeneous unit search cost, $c(>0)$.

We assume that experts cannot differentiate between customers who are going to them for a first opinion and those who are going to them for a second opinion. Thus, experts can not change their service recommendations for the two types of customers. Moreover, we as sume that the expert will not recommend $c_{L}$ service for a H-problem because of the liability rule which penalizes the expert who cannot fix the problem.

A customer's payoff depends on the severity of the problem and the type of service purchased. We denote the payoff of a customer who has severity $t \in\{L, H\}$ and who purchased the service $s \in\left\{c_{L}, c_{H}\right\}$ at $\mathrm{n}$-th consultation by $u(s \mid t, n)$.

$$
\begin{aligned}
u\left(c_{L} \mid L, n\right)=B & -P_{L}-n(c+d) \\
>u\left(c_{H} \mid L, n\right) & =u\left(c_{H} \mid H, n\right) \\
& =B-P_{H}-n(c+d) \\
& >u\left(c_{L} \mid H, n\right) \\
& =-P_{L}-n(c+d)
\end{aligned}
$$

$\mathrm{B}(<\infty)$ denotes the benefit of recovering from problem in pecuniary term and the state at which customers have problem is evaluated as zero. $P_{t}$ is the regulated price ${ }^{3)}$ for pur- chasing $c_{t}$-service $t \in\{L, H\}$ and regulated as $P_{L}<P_{I I}$. These relations show that customers who have L-problem prefer purchasing $c_{L}$-service to $c_{H}$-service and those who have $\mathrm{H}$-problem prefer $c_{H}$ service to $c_{L}$-service. We assume that customers are risk-neutral utility maximizers.

An expert obtains a profit only when a customer purchases a service from him. For simplicity, it is assumed that there is no profit from diagnosis ${ }^{4}$. $\pi(s \mid t)$ denotes an expert's payoff for providing a customer with sservice for a t-problem.

$$
\begin{aligned}
& \pi\left(c_{I I} \mid L\right)=\pi\left(c_{H} \mid H\right)=P_{H}-c_{I I}>\pi\left(c_{L} \mid L\right) \\
& =P_{L}-c_{L}>\pi\left(c_{L} \mid H\right)=-\infty
\end{aligned}
$$

This inequality indicates that an expert prefers to provide $c_{H}$-service to $c_{L}$ service regardless of the problem type ${ }^{5)}$. We assume that experts are risk-neutral profit maximizers.

Customers have four information sets, $c_{l, 1}$, $c_{H 1}, c_{L 2}$, and $c_{H 2}$. $c_{t n}$ means that a customer is prescribed $c_{t}$-service $t \in\{L, H\}$ at the $\mathrm{n}$-th visit $n \in\{1,2\}$. With information sets $c_{L 1}$ and $c_{L 2}$, a customer knows that his problem is a $L$ -

${ }^{3)}$ Price may be a signal of honesty in some markets. Except for such a case, the analysis under the regulated price can be interpreted as a subgame after price setting.

4) When there is a capacity constraint in experts' service, relative profitability among diagnosis, $c_{L}$-service, and $c_{H}$-service have an effect on expert behavior. Emons (1997) applied this to credence goods market.

5) Experts' fraudulent behavior can be resolved by the combination of less profitable $c_{H}$ service than $c_{L}$-service and liability rule. However our concern is what mechanism can discipline experts on the situation fraud is profitable. 
problem since the expert's payoff relation shows that an expert recommends $c_{L}$-service only for a L-problem. Thus, a customer immediately purchases $c_{L}$ service when he is prescribed $c_{L}$ service. Moreover, we assume that it is better for a customer to purchase $c_{H}$-service than no service when he reached $c_{H 2}$ information set, $u$ $\left(c_{H} \mid \cdot, 2\right)>0$. Customer need to make a decision only at $c_{H 1}$. At this information set, he decides whether to seek a second opinion.

Therefore, a customer's behavioral strategy can be represented by the probability of going search, $s$, at $c_{H 1}$.

After nature randomly draws severity for each customer, experts can identify severity through diagnosis. Experts have two information sets, $\mathrm{L}$ and $\mathrm{H}$, according to their customers' type. When a customer has a H-problem, an expert's only option is prescribing $c_{H}$ service because of the liability rule. On the o ther hand, if their customer has a L-problem, they can choose $c_{L}$-service or $c_{H}$-service. When we denote the probability that experts prescribe $c_{L}$-service for L-problem by $\lambda$, the behavioral strategy of experts can be represented by $\lambda$ at information set $\mathrm{L}$.

It is assumed that every game structure except experts' private information is common knowledge. We use perfect Bayesian equilibrium (PBE) as solution concept in following analysis.

\section{Equilibria and Diamond's Problem}

Our basic model in previous chapter has two types of problem severities, $\mathrm{L}$ and $\mathrm{H}$, and two types of services, $c_{L}$ and $c_{H}$. We call this feature two-type assumption. Previous studies usually utilized two-type assumption in modeling search behavior and they showed that there were desirable equilibria. In following proposition 1-3, we demonstrate that desirable equilibria in which experts transmit the true information to customers exist under two-type assumption.

We focus on the symmetric perfect Bayesian equilibria in which every expert adopts the same strategy, $\lambda$, and every customer has same strategy, $s$, in the following analysis.

As we mentioned, a customer's optimal behavior at information sets, $c_{L 1}$, $c_{L 2}$, and $c_{H 2}$, is trivial. Thus, proposition 1 summarizes a customer's optimal search rule, $s$, which denote the probability of seeking a second opinion at information set $c_{H 1}$.

Proposition 1 (Optimal Search) A customer's optimal search rule is $S^{*}(\lambda)$, Where

$$
\begin{aligned}
& \text { (C1) } c+d>m^{*}\left(P_{H}-P_{L}\right) \\
& s^{*}(\lambda)=0 \\
& \text { (C2) } c+d \leq m^{*}\left(P_{I I}-P_{L}\right)
\end{aligned}
$$

$s^{*}(\lambda)= \begin{cases}0 & \text { if } \lambda \in\left[0, \lambda_{s 1}\right) \\ {[0,1]} & \text { if } \lambda=\lambda_{s 1} \\ 1 & \text { if } \lambda \in\left[\lambda_{s 1}, \lambda_{s 2}\right) \\ {[0,1]} & \text { if } \lambda=\lambda_{s 2} \\ 0 & \text { if } \lambda \in\left(\lambda_{s 2}, 1\right]\end{cases}$

where $m^{*}=\max _{\lambda \in[0,1]} \lambda(1-\lambda) /(2-\lambda), \lambda_{s 1}$ and $\lambda_{s 2}$ are the two solutions of equation $\lambda$ (1$\lambda)\left(P_{H}-P_{L}\right) /(2-\lambda)=c+d$, and $\lambda_{s 1} \leq \lambda_{s 2}$ (equality is satisfied at $m^{*}\left(P_{I I}-P_{L}\right)=c+d$ ).

Proof. A customer's optimal search rule can be derived by comparing the payoff from 
accepting the offer with the payoff from seeking a second opinion. Let $p\left(\left.t\right|_{H 1}\right)$ denote a customer's belief that he has t-problem $t \in\{L$, $H$ \} given that he reached information set $c_{H 1}$. When experts' strategy is given by $\lambda$, a customer's belief can be computed as $p\left(\left.L\right|_{H 1}\right)=$ $(1-\lambda) /(2-\lambda), p\left(H||_{H 1}\right)=1 /(2-\lambda)$ by using Bayes' rule. A customer's expected payoff from accepting the offer at $c_{H 1}$ is given by,

$$
\begin{aligned}
E u\left(\text { accept }\left.\right|_{H 1}\right)= & p\left(\left.L\right|_{C_{H 1}}\right) u\left(c_{H} \mid L, 1\right) \\
& +p\left(\left.H\right|_{H 1}\right) u\left(c_{H} \mid H, 1\right) \\
= & B-P_{H}-(c+d)
\end{aligned}
$$

On the other hand, when a customer chooses to seek a second opinion, he may receive $c_{L}$-recommendation with probability $p\left(c_{L} \mid S\right)=$ $\frac{\lambda(1-\lambda)}{2-\lambda}$ or $c_{H}$-recommendation with probability $p\left(c_{H} \mid S\right)=\frac{1+(1-\lambda)^{2}}{2-\lambda} . \quad$ A customer's expected payoff from searching is given by,

$$
\begin{aligned}
& E u\left(\operatorname{search} \mid c_{H 1}\right)=p\left(c_{L} \mid S\right) u\left(c_{L} \mid L, 2\right)+p\left(c_{H} \mid S\right) u\left(c_{H} \mid H, 2\right) \\
&=B-P_{H}+\frac{\lambda(1-\lambda)}{2-\lambda}\left(P_{H}-P_{L}\right)-2(c+d)
\end{aligned}
$$

Customers' optimal search rule is $s=0$ if $E u\left(\operatorname{accept} \mid c_{H 1}\right)>E u\left(\operatorname{search} \mid c_{H 1}\right), s=1$ if $E u$ (accept| $\left.c_{H 1}\right)<E u\left(\operatorname{search} \mid c_{H 1}\right)$, and $s=[0,1]$ if $\mathrm{Eu}\left(\left.\operatorname{accept}\right|_{C_{H 1}}\right)=E u\left(\operatorname{search} \mid c_{H 1}\right)$.

An expert's optimal behavior can be summarized by 1) prescribing $c_{H}$-service at information set $\mathrm{H}$ and 2) prescribing $c_{L}$-service with probability $\lambda$ or $c_{I I}$-service with probability 1 $\lambda$ for L-problem. $c_{L}$-recommendation gives them low profit $\pi\left(c_{L} \mid L\right)$ with certainty, while $c_{H}$-recommendation brings high profit $\pi\left(c_{H} \mid L\right)$ with uncertainty. The next proposition gives the best (symmetric) response at information set L.

Proposition 2 An expert's symmetric best response is $\lambda^{*}(s)$, where

$\lambda^{*}(s)= \begin{cases}0 & \text { if } s \in\left[0, \mathrm{~s}_{1}\right) \\ \left\{0, \lambda_{m}, 1\right\} & \text { if } s \in\left[\mathrm{s}_{1}, \mathrm{~s}_{2}\right] \\ 1 & \text { if } s \in\left(\mathrm{s}_{2}, 1\right]\end{cases}$

where $S_{1}=\frac{\pi\left(c_{H} \mid L\right)-\pi\left(c_{L} \mid L\right)}{\pi\left(c_{H} \mid L\right)}$,

$$
S_{2}=\frac{\pi\left(c_{H} \mid L\right)-\pi\left(c_{b} \mid L\right)}{\pi\left(c_{L} \mid L\right)},
$$

and $\lambda_{m}=\frac{\pi\left(c_{H} \mid L\right)-(1+s) \pi\left(c_{L} \mid L\right)}{s\left(\pi\left(c_{l l} \mid L\right)-\pi\left(c_{L} \mid L\right)\right)}$.

Proof. Each expert has an equal number of customers who have L-problem and who are going to an expert for a first opinion because we assumed that customers randomly select the expert they visit first. Customers who are prescribed $c_{L}$-service purchase $c_{L}$-service from the expert they consulted with probability one, while customers who are prescribed $c_{H}$-service

\begin{tabular}{|c|c|c|}
\hline & $c_{L}$ & $c_{H}$ \\
\hline$c_{L}$ & $\pi\left(c_{L} \mid L\right), \pi\left(c_{L} \mid L\right)$ & $(1+s) \pi\left(c_{t} \mid L\right),(1-s) \pi\left(c_{H} \mid L\right)$ \\
\hline$c_{H}$ & $(1-s) \pi\left(c_{H} \mid L\right),(1+s) \pi\left(c_{L} \mid L\right)$ & $\pi\left(c_{H} \mid L\right), \quad \pi\left(c_{H} \mid L\right)$ \\
\hline
\end{tabular}
search with probability $s$. The following matrix represents the expert's payoff of experts from L-problem customers when a customer's search strategy is $s$. In each cell, the first (second) number represents the row (column) player's payoff multiplied by four.

When the column expert uses strategy $\lambda_{2}$, the row expert's expected payoff by taking action $c_{L}$ is given by,

$$
\begin{aligned}
E \pi\left(c_{L} \mid L\right) & =\lambda_{2} \pi\left(c_{L} \mid L\right)+\left(1-\lambda_{2}\right)(1+S) \pi\left(c_{L} \mid L\right) \\
& =\left(1-\lambda_{2} S+S\right) \pi\left(c_{L} \mid L\right)
\end{aligned}
$$


The row expert's expected payoff by taking action $c_{H}$ is given by,

$$
\begin{aligned}
E \pi\left(c_{H} \mid L\right) & =\lambda_{2}(1-S) \pi\left(c_{H} \mid L\right)+\left(1-\lambda_{2}\right) \pi\left(c_{H} \mid L\right) \\
& =\left(1-\lambda_{2} S\right) \pi\left(c_{H} \mid L\right)
\end{aligned}
$$

Thus, the row expert's best response, given $\lambda_{2}$ and $s$, can be summarized as follows by comparing $E \pi\left(c_{L} \mid L\right)$ with $E \pi\left(c_{H} \mid L\right)$.

i ) $\mathrm{S}<\frac{\pi\left(C_{H} \mid L\right)-\pi\left(C_{L} \mid L\right)}{\pi\left(c_{H} \mid L\right)}$

$$
\lambda_{1}^{*}\left(\lambda_{2}, s\right)=0 \text { for any } \lambda_{2} \in[0,1]
$$

ii $) \frac{\pi\left(c_{H} \mid L\right)-\pi\left(c_{i} \mid L\right)}{\pi\left(c_{H} \mid L\right)} \leq \mathrm{s} \leq \frac{\pi\left(c_{H} \mid L\right)-\pi\left(c_{L} \mid L\right)}{\pi\left(c_{L} \mid L\right)}$

$$
\lambda_{1}^{*}\left(\lambda_{2}, s\right)= \begin{cases}0 & \text { if } \lambda_{2} \in\left[0, \lambda^{*}\right) \\ {[0,1]} & \text { if } \lambda_{2}=\lambda^{*} \\ 1 & \text { if } \lambda_{2} \in\left(\lambda^{*}, 1\right]\end{cases}
$$

iii) $\frac{\pi\left(c_{H} \mid L\right)-\pi\left(c_{L} \mid L\right)}{\pi\left(c_{L} \mid L\right)}<\mathrm{s}$

$$
\lambda_{1}{ }^{*}\left(\lambda_{2}, s\right)=1 \text { for any } \lambda_{2} \in[0,1]
$$

The column expert's best response, given $\lambda_{1}$ and $s$, can be derived by exchanging $\lambda_{1}$ and $\lambda_{2}$ in correspondence i)-iii). The Symmetric best response for $s$ is obtained by calculating $\lambda$ satisfying $\lambda=\lambda_{1}^{*}(\lambda, s)=\lambda_{2}^{*}(\lambda, s)$.

Symmetric PBE are derived from proposition 1-2. In order to express PBE assessment, we define customers' beliefs (B) by using Bayes' rule. The following four tuple correspond to the probabilities customers have in the event they have L-problem at $c_{L 1}, c_{H 1}, c_{L 2}$, and $c_{H 2}$, respectively.

(B) $\left(1, \frac{1-\lambda}{2-\lambda}, 1, \frac{(1-\lambda)^{2}}{1+(1-\lambda)^{2}}\right)$ where $\lambda$ corresponds to an expert's equilibrium strategy in (E1)-(E3) of proposition 3. As we mentioned before, customers accept experts' offer at information sets, $c_{L 1}, c_{L 2}$, and $c_{H 2}$, and experts prescribe $C_{H}$-service at information set $H$. The next proposition describes customers' strategy only at $c_{H 1}$ and experts' strategy only at $\mathrm{L}$.

Proposition 3 (Symmetric PBE) . When (C1) is satisfied, the unique PBE assessment consists of (E1) and (B). When (C2) is satisfied, there are three symmetric PBE which consist of (E1) - (E3) and (B) except when (E2) coincides with (E3).

(E1) Experts always prescribe $c_{H}$-services for L-problem and customers accept the offer without searching.

(E2) Experts prescribe $c_{L}$-service with probability $\lambda_{s 1}$, or $c_{H}$-service with probability $1-\lambda_{s 1}$. Customersaccept $c_{H}$-recommendation with probability $1-\lambda^{*-1}\left(\lambda_{s 1}\right)$ or search with probability $\lambda^{*-1}\left(\lambda_{s 1}\right)$.

(E3) Experts prescribe $c_{L}$-service with probability $\lambda_{s 2}$ or $c_{I I}$-service with probability $1-\lambda_{s 2}$. Customersaccept $c_{H}$-recommendation with probability $1-\lambda^{*-1}\left(\lambda_{s 2}\right)$ or search with probability $\lambda^{*-1}\left(\lambda_{s 2}\right)$.

Proof. When belief system is given by (B), sequential rationality has been already confirmed in proposition 1 and 2. Belief (B) is computed by using Bayes' rule. Thus, (E1)(E3) with (B) are PBE.

Equilibria (E2) and (E3) in proposition 3 are the main achievements of the search model and these are desirable equilibria we 
mentioned before. The information about state of nature is transmitted from the perfectly informed expert (sender) to the uninformed customer (receiver). Indeed, a customer who receives a $c_{L}$-recommendation thinks that he has a L-problem with probability one and a customer who received $c_{H}$-recommendation thinks that he has Hproblem with probability $1 /(2-\lambda)(>1 / 2$ if $\lambda>0)$. In other words, an expert's recommendation makes it possible for a customer to form more precise posterior beliefs.

The driving force of information transmission is competition among experts under the threat of customer search. If there is no competitive expert other than himself in the market, $c_{L}$-service will never be prescribed in a unique Nash equilibrium because the expert prefers prescribing $\epsilon_{H}$-service and customers prefer purchasing any service to boycotting it. In this sense, customer search makes competition among experts effectively function and this result provides the grounds for insisting that customer search works as a device for disciplining experts' fraudulent behavior in previous studies.

However, the two-type assumption is crucial and the desirable equilibria in the search model disappear by altering the two-type assumption. Usually, the two-type assumption is used for simplifying analysis in game theory. For example, two types of workers such as those with high- and low-ability are utilized in the job market signaling model and two types of consumers such as those with highand low-risk are employed in the insurance contract model. In order to make it possible to treat the two-type assumption as an assump- tion for simplicity, it is necessary that the main result and comparative static results from a model are not changed by altering the twotype assumption. Indeed, above-mentioned two examples satisfy this robustness, while our search model does not.

The following proposition generalizes our basic model by replacing the two-type assumption with the continuum type assumption. The continuum type assumption is more general and plausible than the two-type assumption because there are moderate severities and services in between $\mathrm{L}$ and $\mathrm{H}$. We put the following four assumptions about the problem and service type in place of the original assumptions. We show that the desirable result of the search model cannot be extended to more general situation.

(A1) There is a continuum type of customer's problems. Without loss of generality, we denote type space $\mathrm{T}$ by interval $[0,1]$. The order of the number coincides with severity.

(A2) There is a continuum type of services $c(t), t \in T . c(t)$-service can fix the problem $t^{\prime}$ where $t^{\prime} \leq t$ but not problem $t^{\prime \prime}$ where $t^{\prime \prime}$ $>t$.

(A3) Price of $c(t)$-service, $\mathrm{P}(\mathrm{t})$, and experts' profit from providing $c(t)$ - service, $\pi$ $(t)$ are strictly increasing functions of $t$.

(A4) It is beneficial for a customer to purchase the most expensive service, $P(1) \leq B$.

Proposition 4 (Diamond's Problem) Let us replace the original model's assumptions with (A1)-(A4). There is a unique Nash equilibrium such that experts always prescribe c(1)service regardless of severity and customers accept the offer without searching. 
Proof. The proof is simple because this new game is solvable by iterated strict domina nce. For a simple presentation, we assumed that if the cheapest purchasing cost with a search is equal to the status quo price, customers do not search.

Step 1: $t_{1}$ is defined by $t_{1}=\min \left\{P^{-1}(P(0)\right.$ $\left.+c+d), P^{-1}(1)\right\}$. If customers are prescribed $c\left(t^{\prime}\right)$-service, $t^{\prime} \in\left[0, t_{1}\right]$, they will not search because the cheapest result of the search is greater than or equal to status quo, $P(0)+c$ $+d \geq P\left(t^{\prime}\right)$ for $t^{\prime} \in\left[0, t_{1}\right]$.

Experts know this customer's behavior. Therefore, prescribing $c\left(t^{\prime}\right), t^{\prime} \in\left[0, t_{1}\right)$ is strictly dominated by prescribing $c\left(t_{1}\right)$ since the expert's profit is a strictly increasing function of the type of problem. Prescribing $c\left(t^{\prime}\right)$, $t^{\prime} \in\left[0, t_{1}\right)$ is deleted from the expert's pure strategy in this step.

If $P\left(t_{1}\right)=P(1)$, the game is solved. Otherwise, we proceed to the second step.

Step 2: $t_{2}$ is defined by $t_{2}=\min \left\{P^{-1}\left(P\left(t_{1}\right)\right.\right.$ $\left.+c+d), P^{-1}(1)\right\}$. In the same way as in step 1 , prescribing $c\left(t^{\prime}\right), t^{\prime} \in\left[t_{1}, t_{2}\right)$ is deleted from the expert's pure strategy in this step.

If $P\left(t_{2}\right)=P(1)$, the game is solved. Otherwise, we proceed to next step.

This process will be iterated until the $n^{*}$ th step in which $P\left(t_{n^{*}-1}\right)+c+d \geq P$ (1) is reached. $n^{*}$ is well defined since the range of price is bounded. Through this process, only $c$ (1) survives the iterated deletion of strictly dominated strategy. When experts use such a strategy, search is strictly dominated by nonsearch strategy for customers. Proposition 4 is proved because the unique solution of iterated strict dominance is a unique Nash equilibrium.
Proposition 4 says that the desirable equilibria vanish in the search model by altering the two-type assumption into a more general one. This is similar to Diamond's problem.

The fact means that the two-type assumption is crucial in obtaining the desirable result but cannot be interpreted as an assumption for simplicity. Moreover, customer search is not an effective device for preventing experts from engaging in fraudulent behavior in the general situation.

We note that the desirable equilibria also disappear under the two-type assumption when the sum of the diagnosis and search cost (broad search cost) is large, that is, when condition (C1) in proposition 1 is satisfied. However, the latter fact is totally different from proposition 4. Let us assume the price of the least (most) expensive service in assumption (A3) is equal to the price of $c_{L}$-service $\left(c_{H}\right.$-service), $P(0)=c_{L}, P(1)=c_{H}$. In proposition 4 , even when the difference between the least and the most expensive price is large in comparison with the broad search cost, or in other words, even when the condition (C1) in proposition 1 is dissatisfied, a unique Nash equilibrium results in maximum fraud if there is a ladder which bridges the gap between the minimum and the maximum price.

Proposition 4 raises skepticism about the effectiveness of search mechanism in a credence goods market. Usually, experts charge customers for diagnosing a problems. This suggest that the broad search cost is likely to be strictly positive and that conditions under which proposition 4 is attained are likely to be satisfied. Although Diamond's problem is paradoxical, at least at the theoretical level, 
our result shows the limitation of customer search which was effective in previous studies as a device for preventing fraudulent behavior by experts.

The continuum type assumption in proposition 4 may also seem to be unrealistic, but it is clear from the proof that the assumption is not essential for obtaining proposition 4.

A finely partitioned discrete type assumption brings the model to the same equilibrium. We slightly alter assumptions (A1)-(A4) to introduce a discrete type, and the following corollary shows the result of proposition 4 is maintained.

(A1') There are $\mathrm{N}$ types of customers' problem, $t^{i} \in[0,1] i=1,2, \cdots, N$.

Moreover we assumed that $t^{0}=0, t^{N}=1$, and $t^{i-1}<t^{i}$ for $j=2, \cdots, \mathrm{N}$.

(A2')-(A4') Functions $c(\cdot), P(\cdot)$, and $\pi(\cdot)$ are redefined on discrete types.

(A5) $P\left(t^{i+1}\right)-P\left(t^{i}\right)<c+d$ for $j=1,2, \cdots$, $N-1$.

Corollary 1 Let us assume ( $\left.A 1^{\prime}\right)$-( $\left(A 4^{\prime}\right)$ and (A5). There is a unique Nash equilibrium such that experts always prescribe $c$ (1)-service regardless of severity and customers accept the offer without searching.

Proof. The new game is also dominance solvable in the same way as proposition 4 .

The results of proposition 4 and corollary 1 have destructive impact on the search model in a credence goods market. If the interval of the fixing cost becomes less than the broad search cost, $P\left(t^{j+1}\right)-P\left(t^{j}\right)<c+d$, the unique Nash equilibrium results in maximum fraud, regardless of how expensive the service is and how many experts there are. From a different point of view, competition among experts is no longer effective in disciplining experts under condition $(\mathrm{A} 5)^{6)}$.

The mechanism which collapses desirable equilibrium in our model is essentially the same as the mechanism in Diamond's problem. Whether search cost is zero or not was critical condition in Diamond's problem because product's price can be continuously changed. Similarly, in our model, (A5) is critical condition since the price of service is discrete in corollary 1.

\section{Concluding Remarks}

What mechanism can prevent experts from engaging in fraudulent behavior in a credence goods market? Customer search was one promising candidate for solving the problem with in the market organization. Indeed, some authors applied the search model to the market for expert services; the model showed that there is an equilibrium where experts transmit true information to customers.

However, we show that such a desirable equilibrium vanishes by replacing the original assumptions with more plausible assumptions" ${ }^{7}$. Let's call the sum of the search cost

6) Milgrom and Roberts (1986) demonstrated that competition among interested parties promoted information revelation to a decision maker in persuasion game. This is because interested parties sent information to decision maker without charge. However, if decision maker should have to pay fees to receive information, competition no longer works. 
and the diagnosis cost, the broad search cost. Our pes-simistic result of the search model demonstrates that a unique Nash equilibrium results in maximum fraud when the fixing cost interval is less than broad search cost. As long as this condition exists, experts prescribe the most expensive service and customers accept their offer without searching, no matter how large the difference between maximum and minimum price is and how many experts there are. Indeed, even a slight positive broad search cost results in maximum fraud when the fixing cost is continuously changeable.

Usually, experts charge customers nonnegligible amount for diagnosing a problem. This suggest that the broad search cost is likely to satisfy the previous condition. Customer search is likely to fail as a method to discipline experts. At least at the theoretical level, our results show the limitation of using the search model as a device for preventing fraudulent behavior by experts.

Some institutions may exist to resolve Diamond's problem in credence goods market. Wolinsky's (1993) vertical specialization scenario provide us one possibility. Experts can make a commitment to provide particular range of services through specialization. Thus customers can avoid maximum fraud by starting their search from a less expensive range.

\section{References}

Darby MR and Karni E (1973) "Free Competition and the Optimal Amount of Fraud," The Journal

\footnotetext{
${ }^{7}$ Needless to say, original models have some devices to avoid the Diamond's paradox such as consumers who have zero search cost.
}

of Law and Economics. $16: 67-88$.

Diamond PA (1971) "A Model of Price Adjustment," Journal of Economic Theory. 3(2) : 156-168.

Emons W (1997) "Credence Goods and Fraudulent Experts," Rand Journal of Economics. 28 : 107-119. Izumida N, Nakanishi S and Urushi H (1999) "New Entrance Regulation of Physicians and Medical Expenditure: Expenditure Function Approach for Physician Inducement Demand Hypothesis (in Japanese)," Journal of Health Care and Society. 37 (3) : 246-258.

Kishida K (2001). "Supplier Induced Demand Hypothesis Versus Decline of Access Cost Hypothesis : Analysis with Panel Data of Second Medical Areas and Cities (in Japanese)," The Quarterly of Social Security Research. 37 (3) : 246-258.

McMillan J and Rothschild M (1994) "Search," in Handbook of Game Theory with Economic Applications ; eds. by Aumann RJ and Hart S. 905-927; Elsevier Science Publishers B.V.

Milgrom P and Roberts J (1986) "Relying on the Information of Interested Parties," Rand Journal of Economics. 17(1) : 18-32.

Nishimura S (1987) Iryo no Keizaigaku. Toyokeizaishinposha.

Pitchik C and Schotter A (1993) "Information Transmission in Regulated Markets," Canadian Journal of Economics. $26: 815-829$.

Stiglitz JE (1989) "Imperfect Information in the Product Market," in Handbook of Industrial Organization; eds. by Schmalensee $\mathrm{R}$ and Willig RD. 769-847 ; Elsevier Science Publishers B.V.

Suzuki R (1997) "Gairai Iryo to Ishi Mitsudo," in Roujin Iryo Reseputo Data Bunseki Jigyo 1996 Kenkyu Houkokusho. Koushu Eisei Shinkoukai.

Wolinsky A (1993) "Competition in a Market for Informed Experts' Services," Rand Journal of Economics. 24 : 380-398.

Yamada T (2002) "An Econometric Analysis on Supplier Induced Demand Hypothesis (in Japanese)," The Quarterly of Social Security Research. 38(1): 39-51. 


\title{
信用財市場における探策行動の限界
}

\begin{abstract}
青 木 研*
エキスパート・サービスの市場では, エキスパートが情報上優位にあることを利用 して機会主義的な行動をとることが問題になる。医師による需要誘発などは，エキス パート（医師）の機会主義的行動の好例であろう。そこでは, エキスパートの機会主 義的な行動をいかに抑制するかが中心的な課題となる。先行する諸研究では, 消費者 の探策行動が, 機会主義的行動を防ぐうえで有効であるとされてきた。しかしながら, 本研究では, 先行研究で簡単化のために用いられていたある仮定を緩めると, 消費者 の探策行動が全く有效でなくなってしまうことを示した。

エキスパートが真実を伝達する均衡が消失する理由は, 原占市場で正の探策コスト がかかる時にダイアモンド・パラドックスが発生する理由と類似している。消費者は 探策行動をとることにあらかじめコミットできないのが主な理由である。エキスパー ト・サービス市場での機会主義的行動を防ぐメカニズムについて, 少なくとも理論的 なレベルでは更なる研究が必要である。

キーワード：エキスパート・サービス, 信用財, 非対称情報, サーチ
\end{abstract}

* 上智大学経済学部 